TOURNAMENT NEWS

\title{
The Thirteenth ACM North American Computer Chess Championship
}

\author{
Sponsored by the Association for Computing Machinery \\ Dallas, Texas, October 24-26, 1982
}

NEWSRELEASE

The Thirteenth ACM North American Computer Chess Championship will be held at the Dallas Hilton Hotel in Dallas, Texas on October 24-26 1982 as part of the 1982 ACM Annual Conference. A four-round Swiss-style tournament is planned with rounds beginning at $1 \mathrm{p} . \mathrm{m}$. and $7.30 \mathrm{p} . \mathrm{m}$. on Sunday October 24th, 7.30p.m. on Monday October 25th, and 7.30p.m. on Tuesday October 26th.

Most of the best programs in the world are expected to participate including BELLE, the current world champion, CHAOS, DUCHESS, NUCHESS, and CRAY BLITZ. BELLE, the work of Ken Thompson and Joe Condon of Bell Telephone Laboratories, is playing almost Master level chess and the others are not far behind.

The tournament organizing committee is John Forman, Texas Instruments, Robert Hyatt, University of Southern Mississippi, Cary Duncan, Xerox Computer Services, Ben Mittman, Northwestern University, and Monroe Newborn, McGill University. Mike Valvo, International Master, will act as Tournament Director.

Anyone interested in entering a program or seeking more information should write to Monroe Newborn, School of Computer Science, McGill University, 805 Sherbrooke Street West, Montreal, Quebec H3A 2K6, Canada. Entries close August 10, 1982. 